\title{
КРИТЕРИИ И ОТДЕЛЬНЫЕ АСПЕКТЫ ПРОЦЕДУРЫ ПРИНЯТИЯ НОВЫХ ЧЛЕНОВ ООН
}

Аннотация. В статье рассматриваются критерии принятия государств в качестве новых членов Организации Объединенных Наций, а также отдельные аспекты прочедуры принятия в членство Организациии Объединенных Наций. Рассматривается деятельность Совета Безопасности Организации Объединенных Наций и, в частности Комитета по приему новых членов Совета Безопасности Организачии Объединенных Наций. Указывается, что Комитет достаточно часто пользовался закрепленным за ним полномочием на запрос дополнительной информации у государства-кандидата на членство ООН. Утверждается что принятие новых членов Советом Безопасности и Генеральной Ассамблей в обход данного Комитета носит политизированный характер, тогда как деятельность Комитета позволяет юридически обосновать соответствие (или несоответствие) государства-кандидата на членство критериям ст. 4 Устава Организации Объединенных Наций. Делается вывод о важности деятельности комитета, а не о простом формальной характере его участия в процедуре приема новых членов Организациии Объединенных Наций.

Ключевые слова: ООН, членство, Совет Безопасности, Генеральная Ассамблея, прочедура приема, Комитет, критерии членства, Устав ООН, временные правила, государство

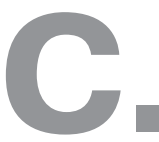

4 Устава ООН регулирует вопросы принятия новых членов этой организации. Первый параграф данной статьи закрепляет ряд условий, позволяющих тому или иному государству претендовать на статус члена ООН, тогда как второй параграф регламентирует процедуру принятия новых государств ООН в качестве нового члена ${ }^{1}$. Таким образом, как условия (критерии), так и процедура принятия новых членов ООН довольно скупо обрисованы Уставом организации, что на практике привело к некоторым сложностям в применении. Как следствие, условия (критерии) принятия новых членов и процедура их принятия, были уточнены рядом резолюций Генеральной Ассамблеи, а также всеобщей практикой.

Напомним критерии принятия новых государств в качестве членов $\mathrm{OOH}$, а также документы организации, которые были направлены на уточнение их смысла и различных аспектов процедуры принятия государств в ОOH.

\footnotetext{
${ }^{1}$ Право международных организаций / Под ред. И.П. Блищенко, А.Х. Абашидзе. - М: РУДН, 2013. С.298 .
}

Основными резолюциями Генеральной Ассамблеи, касающиеся данных вопросов, стали: резолюции № 197 от 8 декабря 1948 г. и № 506 от 1февраля 1952 г. о приёме новых членов ${ }^{2}$. В свою очередь, критериями принятия новых членов являются (ст. 4 Устава ООН):

- наличие государственности. Иначе говоря, в качестве нового члена организации может быть принято только государство, которое, по определению, обладает четко определенной территорией, населением и политической властью;

- $\quad$ миролюбивый характер государства. Что,на наш взгляд, является высоко политизированным критерием, так как миролюбивость является сугубо оценочным, или субъективным критерием;

- принятие обязательств Устава ООН, возможность и желание их исполнения государством-кандидатом.

В соответствии с параграфом 2 ст. 4 Устава $\mathrm{OOH}$, процедура принятия новых членов ООН

\footnotetext{
${ }^{2}$ Répertoire de la pratique des NU, I, 1955, p. 177-218 et suppl.
} 1, 1959, p. 81-92 
предполагает участие Совета Безопасности, который предлагает кандидатуру государства Генеральной Ассамблее, которая принимает окончательное решение. Стоит отметить, что с юридической точки зрения участие Совета носит рекомендательный характер, но на практике, Генеральная Ассамблея не может принять нового члена без «согласия» Совета Безопасности. В реальности процедура принятия новых членов зависит от внешнеполитических договоренностей между ведущими державами мира, обладающими постоянным членством в Совете Безопасности ${ }^{3}$. Как следствие, с научной, юридической точки зрения выделение конкретных критериев принятия того или иного государства в качестве нового члена ООН на основе ст. 4 Устава ООН, как и исследование процедуры их принятия является довольно сложным делом в связи с высокой политизированностью данного процесса. В связи с этим, юридическое исследование критериев по приему новых членов может быть осуществлено лишь при помощи основных актов Организации (напримерВременных правил процедуры Совета Безопасности $\mathrm{OOH}^{4}$, где существует специальная глава, посвященная приему новых членов (Глава X, ст. 58-60)), а также при исследовании практики деятельности Комитета по приему новых членов Совета Безопасности ООН.

Действительно, именно участие последнего в процедуре принятия новых членов позволило деполитизировать ее, тогда как принятие новых членов ООН в обход указанного Комитета, носило

\footnotetext{
${ }^{3}$ Так, например, в второй половине двадцатого века в период противостояния двух блоков государств (коммунистического и капиталистического), принятие новых членов было высоко политизированным процессом, где принятие государств, принадлежащих одному блоку, «обменивалось» на принятие государств, принадлежащих другому блоку. Как следствие, говорить о каких-либо точных юридических критериях было довольно сложно. См. M.-C. Dock, Le retrait des Étatsmembres des organisationsinternationales de la famille des NU, Annuairefrançais de droit international, 1994, p. 104

${ }^{4}$ Приняты Советом Безопасности на его первом заседании и изменены на его $31,41,42,44$ и 48-м заседаниях 9 апреля, 16 и 17 мая, 6 и 24 июня 1946 года; 138-м и 222-м заседаниях 4 июня и 9 декабря 1947 года; 468-м заседании 28 февраля 1950 года; 1463-м заседании 24 января 1969 года, 1761-м заседании 17 января 1974 года и 2410-м заседании 21 декабря 1982 года.Предыдущие издания временных правил процедуры были изданы под индексом S/96 и Rev. 1-6.
}

довольно политизированный (неюридический) характер 5 . Стоит, например, упомянуть о случае с принятием в качестве членов Организации Северной и Южной Кореи, которое произошло без участия указанного Комитета. Действительно, Совет Безопасности в своей рекомендации по принятию данных государств в качестве членов не ссылаясь на критерии ст. 4 Устава ООН просто указал, что «желания народов Корейской Народной Демократической Республики и республики Корея гармонично совпали. В связи с чем Совет решил принять одновременное решение о принятии двух частей Корейского полуострова» ${ }^{6}$. Таким образом, процедура принятия новых членов Советом безопасности и Генеральной Ассамблеей в обход указанного Комитета, которая стала регулярной практикой с конца 40-х гг. вплоть до 1971 г., привела к политизированности процедуры, а также к размыванию критериев ст. 4 Устава ООН, так как в упомянутом примере Совет никоим образом на них не ссылается.

Из выше упомянутых актов и отдельных аспектов практики принятия новых членов, становится очевидным, что основные аспекты приема новых членов (как процедуры, так и критерии) определяются, главным образом, именно Советом Безопасности. Более того, сама процедура принятия того или иного государства начинается с Совета Безопасности, о чем свидетельствует даже п. 2 ст. 4 Устава ООН, а чаще всего (на практике) с одного из его постоянных комитетов - Комитета по приему новых членов.

В соответствии со ст. 58 и 59 Временных правил процедуры Совета Безопасности ООН, процедура принятия нового государства в качестве члена $\mathrm{OOH}$, осуществляется по заявлению соответствующего государства, которое по прохождении отдельных формальностей (направлении заявки Генеральному секретарю и Совету Безопасности),

\footnotetext{
${ }^{5}$ В соответствии со ст. 59 Временных правил процедуры Совета Безопасности $\mathrm{OOH}$, Совет не обязан направлять заявление государства-кандидата в Комитет, так как вторая фраза данной статьи содержит следующую формулировку: «Если Совет Безопасности не примет иного решения, то это заявление направляется Председателем в комитет ..."

${ }^{6}$ Security Council Presidential Statement, S/22911, 8 Aug 1991.

${ }^{7}$ S. Bailey, S.Daws, The Procedure of the UN Security Council, $2^{\text {nd }}$ ed. $, 1998,339-44$.
} 
рассматривается по существу в Комитете по приему новых членов (за исключением случаев когда Совет примет иное решение). Именно последний представляет Совету свои заключения по приему того или иного государства (ст. 59), где в отличие от политизированных заявлений, которые мы можем обнаружить в рекомендациях Совета, мы обнаружим конкретное исследование обстоятельств, свидетельствующих о соблюдении государствомкандидатом критериев ст. 4 Устава ООН.

В первые годы существования $\mathrm{OOH}$ данный Комитет разработал несколько резолюций, уточнивших отдельные аспекты процедуры приема новых членов, которые в последствии были утверждены Советом ${ }^{8}$. Так, в частности, комитет установил за собой право запрашивать у государствакандидата на членство в ООН любую информацию, позволяющую данному постоянному органу Совета Безопасности определить соответствует ли данная кандидатура критериям, установленным в основополагающих актах организации 9 .

На практике Комитет достаточно часто пользовался закрепленным за ним полномочием на запрос дополнительной информации у государства-кандидата на членство ООН. Так, в частности, в ходе подготовки заключения о членстве Иордании, Комитетом была запрошена следующая дополнительная информация:

- $\quad$ с средствах поддержания политической независимости и территориальной целостности Иорданского Хашимитского Королевства;

- $\quad$ о бюджете государства с уточнениями о статьях его доходов и расходов;

- $\quad$ о действии соглашения, подписанного22 марта 1946 г. между Иорданией и Великобританией, в части касающееся территориальной целостности и политической независимости этого государства ${ }^{10}$.

Как видно из вопросов заданных государству-кандидату в данном письме, основной задачей Комитета в данном деле стало выяснение, как

\footnotetext{
${ }^{8}$ Répertoire de la pratique des NU (1945-54) p. 183 ๆ 537 Aug 1946.

9 Там же.

${ }^{10}$ Letter from the Chairman of the Committee on Admission of New Members to the Representative of the Hashemite Kingdom of Transjorden in New York: SCOR 1st year $2^{\text {nd }}$ ser p. 143 supp no 4 annex 7 appendix 18, 15 Aug 1946.
}

фактической, так и юридической независимости Королевства Иордании. Первые два вопроса, касались средств обеспечения независимости этого государства (как политических, так и финансовых), тогда как последний вопрос касался подтверждения международно-правового статуса государства, которое, в частности, отразилось в возможности заключения договора с его бывшей метрополией.

Комитет в качестве ответа получил от Иордании разъяснения, которые коснулись соблюдения положений Устава ООН, наличия у этого государства вооруженных сил; а также соглашения с Великобританией о военно-экономическом сотрудничестве и совместном оборонительном альянсе ${ }^{11}$. Королевство также дало подробные разъяснения, касающиеся его бюджета, уточнив, в частности, статьи доходов и расходов. Наконец, это государство уточнило, что его территориальная целостность и политическая независимость подтверждается тем, что в соответствии с соглашением, подписанным им с Великобританией, отношения с данным государством в военной сфере ограничиваются исключительно сотрудничеством, а также, что данное государство не запрашивало у Иордании разрешения на увеличение количества вооруженных сил, присутствующих на его территории ${ }^{12}$.

Таким образом, Комитет в полной мере воспользовался, закрепленным за ним полномочием по направлению запросов государству-кандидату на предоставление дополнительной информации по его заявке. Более того, данный пример, как и ряд других, свидетельствует о том, что Комитет придерживается требований к кандидатурам, установленным в основных актах $\mathrm{OOH}$, а именно определяет наличие у государства-кандидата его статуса как международно-правового субъекта, политической независимости и т.п.

Тем не менее, содержание запросов Комитета на предоставление дополнительной информации варьировалось в зависимости от различных аспектов политического положения того или иного государства-кандидата. Так, например, при принятии

\footnotetext{
${ }^{11}$ Letter from DjamilTutanji Pasha, Representative of the Hashemite Kingdom of Jordan in New York addressed to the Chairman, Committee on the Admission of New Members, SCOR 1 st year $2^{\text {nd }}$ ser p. 144 supp no 4 annex 7 appendix 18, undated.

12 Там же.
} 
Сиама (Таиланд) в $\mathrm{OOH}^{13}$, двумя постоянными членами Совета Безопасности (Франция и СССР) была выдвинута гипотеза о несоответствии данного государства критериям Устава. Так, Франция считала, что данное государство под прикрытием японских войск захватило территории Лаоса и Камбоджи во время войны, в связи с чем данный член Совета считал, что он находится с этим государством в состоянии войны и, что это государство не является мирным и, соответственно, не соответствует основному критерию членства в $\mathrm{OOH}^{14}$. В свою очередь, СССР указал на отсутствие дипломатических отношений с данным государством.

Сиам ответил на данные замечания следующим образом. В отношении замечаний Франции, данное государство высказало отсутствие формального состояния войны, и что политические силы, которые находятся, на настоящий момент у власти, наоборот, боролись против японских войск. Более того, Сиам сослался на то, что он согласился с французским предложением разбирательства территориального спора в Международном суде ${ }^{15}$. В том, что касается замечаний СССР, Сиам ответил, что он намеревается наладить дипломатические отношения с СССР, в тоже время, дипломатично не уточнив, что данный аспект не является критерием членства в $\mathrm{OOH}$.

В случае с принятием в члены ООН Монголии, Комитет задал государству- кандидату следующие вопросы:

- $\quad$ насколько широки внешнеполитические связи Монголии в экономической, политической, социальной и культурной сферах;

- каково будет развитие внешних сношений этого государства в будущем (в том числе развитие дипломатических и консульских представительств);

- $\quad$ с какими странами (помимо Китая и СССР) данное государство намеревается развить дипломатические отношения;

\footnotetext{
${ }^{13}$ Letter dated 20 May 1946: SCOR 1st year 2nd ser p. 68 supp no. 4 annex 6(3).

${ }^{14} \mathrm{SCOR} 1^{\text {st }} \mathrm{yr} 2^{\text {nd }}$ ser supp no. 4 p. 76 (summary of discussion in Committee on Admission).

15 Данный спор был рассмотрен намного позднее рассмотрения заявки о принятии Сима в качестве члена ООН. См. Case Concerning the Temple of PreahVihear (Cambodia-Thailand), ICJ, Rep. 1962 pp. 6, 28-9.
}

- каково конституционное и институциональное развитие государственных органов Монголии, а также бюджет этого государства. Монголия довольно подробно ответила на поставленные Комитетом вопросы. Ей все же удалось слабо обосновать неразвитость своей дипломатической системы (которая ограничивалась тогда лишь отношениями с Китаем и СССР), а также слабый уровень развития институциональных и финансовых структур государства, которые лишь только создавались в середине двадцатого века ${ }^{16}$.

Случай с принятием в члены Албании стал наиболее сложным для Комитета, что потребовало углубленного анализа кандидатуры этого государства на соответствие критериям ст. 4 Устава ООН. Комитет задал данному кандидату на членство в ООН семь вопросов, что свидетельствовало о широком понимании им своих «следственных» полномочий в отношении заявки:

1. находиться ли Албания в состоянии войны и Грецией,

2. если так, то каким образом данное государство намеревается положить данному состоянию конец,

3. собирается ли албанское правительство применять мирные меры для регулирования конфликтов с другими государствами,

4. действуют ли еще соглашения, подписанные Албанией с другими государствами до 7 апреля 1939 г.,

5. какое отношение у Албании к соглашениям, которые продолжают действовать сегодня, и которые связывают ее с государствами-членами $\mathrm{OOH}$,

6. требование предоставить Комитету информацию по следующим вопросам: об инцидентах на албанско-греческой границе; о расстреле албанской стороной военных судов Великобритании; о содержании греческих граждан в концентрационных лагерях,

7. наконец, Комитет требовал предоставить информацию о результатах недавних выборов в этом государстве ${ }^{17}$.

\footnotetext{
${ }^{16}$ SCOR $1^{\text {st }}$ year $2^{\text {nd }}$ ser supp no. 4 appendix 12 Addendum pp. 124-30.

${ }^{17}$ Letter from the Chairman of the Committee on Admission of New Members to Colonel TukJakova, Minister of State of the Albanian People's Republic dated 9 August 1946 and the ReplyDated 14 August 1946: SCOR 1st yr 2nd ser supp no. 4 Appendix 7 pp. 91-2.
} 
Запрос Комитета о предоставлении информации Албанией отражает сомнение (в частности Греции и Великобритании) в миролюбивом характере этого государства, что, в принципе должно позволить определить соответствует ли данное государство этому критерию членства в ООН. Также (например при рассмотрении пятого вопроса) можно усмотреть желание Комитета убедиться в том, что кандидат готов и будет соблюдать Устав $\mathrm{OOH}$, следовать принципам демократического и правового государства (например седьмой вопрос).

Как и другие кандидаты на вступление в качестве члена в $\mathrm{OOH}$, Албания подробнейшим образом ответила на все поставленные Комитетом вопросы, а также направила ряд документов, свидетельствующих о соблюдении всех необходимых условий членства в ООН.

Из рассмотренных примеров видно, что подход Комитета к членству того или иного государства индивидуализирован и принимает во внимание многие моменты, включая особенности политической и экономической ситуации, положения дел с соблюдением прав человека в государстве-кандидате, а также, что последнее всерьез воспринимает данные запросы.

Все вопросы, адресуемые Комитетом кандидату, касаются исключительно критериев ст. 4 Устава $\mathrm{OOH}$, но на практике их интерпретация Комитетом приняла расширенный характер (так, например, в случае с Монголией рассматривалась развитость дипломатических отношений этого государства, что напрямую не относиться не к одному из критериев членства). Таким образом, мы можем утверждать, что Комитет, в отличие от самого Совета Безопасности, подошел к данному этапу приема в члены государств с большей формальностью и позволил конкретизировать юридические аспекты ст. 4 Устава ООН.

Деятельность Комитета в конце 40-х и начале 50 -х гг. в отношении рассмотрения заявок на принятие в членство ООН затянулась, что вызвало реакцию Генеральной Ассамблеи, которая попросила ускорить процедуру рассмотрения кандидатур. С данной целью, Генеральная Ассамблея посредством резолюции решила несколько скорректировать подход к рассмотрению соответствия критериям ст. 4 Устава ООН. Так, Перу предложила проект резолюции, в соответствии с которым государства-кандидаты должны были бы предъявлять определенную документацию в подтверждение, предоставляемой Комитету информации, подтверждающей соблюдение ими критериев членства в организации. Тем не менее, данное предложение не было принято, но де-факто на практике государства-кандидаты стали предоставлять такую документацию по запросу Комитета.

В итоге, резолюция принятая Генеральной Ассамблеей 18 содержала следующий текст: «Принимая во внимание что суждение Организации относительно того, могут ли и желают ли эти государства выполнять указанные обязательства, а также достойны ли они приема в Организацию со всех иных точек зрения, должно быть основано на таких фактах, как, например, поддержание ими дружественных отношений с другими государствами, выполнение международных обязательств и доказанное желание этих государств и их нынешняя готовность применять при рассмотрении международных притязаний или разрешении международных споров мирные средства, предусматриваемые международным правом (...) Рекомендует чтобы Совет Безопасности пересмотрел все имеющиеся заявления о приеме новых членов; чтобы при этом пересмотре, а также при рассмотрении всех будущих заявлений, члены Совета принимали во внимание все те факты и доказательства, которые государства, подающие заявления могут представить; чтобы Совет основывал свои решения исключительно на условиях содержащихся в Уставе, и на фактах, устанавливающих наличие этих условий».

Таким образом, как практика Комитета, так и положения процитированной резолюции свидетельствуют о том, что критерии членства, установленные ст. 4 Устава ООН, были уточнены. Действительно, как свидетельствует текст резолюции, заявления государств-кандидатов могут быть основаны «...на фактах, устанавливающих наличие этих условий». Так, например, вопрос и ответ государства-кандидата о том, что оно поддерживает миролюбивые отношения с другими государствами подтверждается конкретной информацией о соответствующим поведении этого государства

\footnotetext{
${ }^{18}$ Резолюция Генеральной Ассамблей от 1-го февраля 1952 г. о приеме новых членов, праве государств-кандидатов представлять доказательства, что они удовлетворяют условиям, предусмотренным в статье 4 Устава. A/RES/506 (VI)
} 
(см. выше пример с заявкой Албании). Также, если вопрос о том прибегает ли государство-кандидат к миролюбивым средствам разрешения конфликтов и положительный ответ данного государства на данный вопрос, подтверждаются информацией, или конкретными фактами (см. выше пример с заявкой Сиама).

Таким образом, как рассмотренная практика Комитета, так и резолюция Генеральной Ассамблеи 1952 г., не изменяя смысла п. 1 ст. 4 Устава, конкретизировали его смысл, что позволило полностью имплементировать содержание данного положения. Стоит отметить, что конкретная имплементация смысла и содержания ст. 4 Устава была осуществлена в рамках производства по принятию новых членов, осуществляемого под руководством Комитета, тогда как принятие новых членов в обход Комитета - т.е. Советом Безопасности и Генеральной Ассамблеей, вызывает сомнение в том, проводиться ли все необходимые действия по констатации соблюдения государствами-кандидатами критериев ст. 4 Устава. Тем не менее, рассмотрение новых канди- датур в обход Комитета, все же свидетельствует о желании Совета продемонстрировать, что его деятельность осуществляется в соответствии с практикой разработанной ранее Комитетом, то есть, что он осуществляет проверку соблюдения государством-кандидатом существенных условий ст.4 Устава. Так, например, в случае с принятием в члены Восточного Тимора, рекомендация Совета, в частности, содержала: «Совет..отмечает, что Демократическая республика Восточный Тимор соблюдает содержащиеся в Уставе ООН обязательства и принципы».

Сегодня, процедура проверки заявок государств-кандидатов Комитетом используется с завидной регулярностью. Иначе говоря, Совет Безопасности не рассматривает заявки государствкандидатов собственноручно в обход Комитета, что свидетельствует о том, что кандидатуры государств-заявителей исследуются в полном объеме по формальным критериям установленным ст. 4 Устава $^{19}$. Такой подход носит менее политизированный и, соответственно, более юридический характер в вопросе принятия новых членов ООН.

\section{Библиография:}

1. Case Concerning the Temple of Preah Vihear (Cambodia-Thailand), ICJ, Rep. 1962 pp. 6, $28-9$.

2. Letter dated 20 May 1946: SCOR 1st year 2nd ser p. 68 supp no. 4 annex 6(3).

3. Letter from Djamil Tutanji Pasha, Representative of the Hashemite Kingdom of Jordan in New York addressed to the Chairman, Committee on the Admission of New Members, SCOR $1^{\text {st }}$ year $2^{\text {nd }}$ ser $p .144$ supp no 4 annex 7 appendix 18, undated.

4. Letter from the Chairman of the Committee on Admission of New Members to Colonel Tuk Jakova, Minister of State of the Albanian People's Republic dated 9 August 1946 and the Reply Dated 14 August 1946: SCOR 1st yr 2nd ser supp no. 4 Appendix 7 pp. 91-2.

5. Letter from the Chairman of the Committee on Admission of New Members to the Representative of the Hashemite Kingdom of Transjorden in New York: SCOR 1st year 2nd ser p. 143 supp no 4 annex 7 appendix 18, 15 Aug 1946.

6. M.-C. Dock, Le retrait des États membres des organisations internationales de la famille des NU, Annuaire français de droit international, 1994, p. 104

\footnotetext{
19 Тем не менее, стоит указать, что в зарубежной науке международного права существуют и иные точки зрения. Так в частности утверждается что участие Комитета в процедуре принятия государства в члены ООН является простым участием proforma. См. напримерO'Keefe 'The Admission to the United Nations of the Ex-Soviet and Ex-Yugoslav States', 2001, № 1,Baltic Yearbook of International Law 167, 170-1; Ginther 'Article 4' in SimmaedCommentary 2 ${ }^{\text {nd }}$ ed. p. 185 I 34; Bailey \&DawsThe Procedure of the United Nations Security Council, $3^{\text {rd }}$ ed. n 339-44.
} 
7. O’Keefe 'The Admission to the United Nations of the Ex-Soviet and Ex-Yugoslav States’, 2001, № 1, Baltic Yearbook of International Law 167, 170-1.

8. Répertoire de la pratique des NU (1945-54) p. 183537 Aug 1946.

9. Répertoire de la pratique des NU, I, 1955, p. 177-218 et suppl. 1, 1959, p. 81-92

10. S. Bailey, S. Daws, The Procedure of the UN Security Council, 2nd ed. ,1998, 339-44.

11. SCOR 1st year $2^{\text {nd }}$ ser supp no. 4 appendix 12 Addendum pp. 124-30.

12. SCOR 1st yr $2^{\text {nd }}$ ser supp no. 4 p. 76 (summary of discussion in Committee on Admission).

13. Security Council Presidential Statement, S/22911, 8 Aug 1991.

14. Право международных организаций / Под ред. И.П. Блищенко, А.Х. Абашидзе.-М: РУДН, 2013. С. 298.

15. Резолюция Генеральной Ассамблей от 1-го февраля 1952 г. о приеме новых членов, праве государствкандидатов представлять доказательства, что они удовлетворяют условиям, предусмотренным в статье 4 Устава. A/RES/506 (VI)

\section{References (transliteration):}

1. M.-C. Dock, Le retrait des États membres des organisations internationales de la famille des NU, Annuaire français de droit international, 1994, p. 104

2. O’Keefe 'The Admission to the United Nations of the Ex-Soviet and Ex-Yugoslav States’, 2001, № 1, Baltic Yearbook of International Law 167, 170-1.

3. S. Bailey, S. Daws, The Procedure of the UN Security Council, 2nd ed. ,1998, 339-44.

4. Pravo mezhdunarodnyh organizaciy / Pod red. I.P. Blischenko, A.H. Abashidze.-M: RUDN, 2013. S. 298. 